\title{
Preparation of new ceramic supports macro-porous for microfiltration and ultrafiltration membranes based Moroccan clay
}

\author{
Soulaiman Iaich \& Lahcen Messaoudi \\ (Moulay Ismail University, Faculty of Sciences, Department of Chemistry, Materials Membranes and Processes \\ of Separation Team, PO Box 11201, Zitoune, Meknes, Morocco)
}

\begin{abstract}
The aim of this work is to develop Moroccan clay of the Meknes-Tafilalet region operated as basic raw material for the production of tubular supports mono-channel macro-porous for a microfiltration and ultrafiltration membranes. During the development, several parameters are controlled such as: the chemical and mineralogical composition of the initial powder, the particle size, final sintering temperature and final sintering time. Thus, we have defined a method of preparing of the clay pasta by varying the quantity of added organic matter, the volume of water, the time of mixing and kneading, and the aging time. The supports are obtained by extruding of a plastic paste prepared with a good optimize percentage of the organic matter. These have allowed us to improve the characteristics of the final product such as; the porosity and the mechanical resistance. The supports are dried in the open air, and then treated in an electric furnace at different final sintering temperatures according to a definite thermal program. The results show that the obtained ceramic supports after heat treatment at $1000{ }^{\circ} \mathrm{C}$ for three hours are characterized by a high porosity $(P=36 \%)$, very good chemical resistance $\left(1,11 \%\right.$ for the attack acid $\mathrm{HNO}_{3} / 1 \mathrm{~N}$ and $0,28 \%$ for the attack basic $\left.\mathrm{NaOH} / 1 \mathrm{~N}\right)$, best mechanical performance $(R=190 \mathrm{daN})$ and good permeability to water $\left(F=3329 \mathrm{~L} / \mathrm{h} . \mathrm{m}^{2}\right.$ for $\left.1 \mathrm{bar}\right)$.
\end{abstract}

Keywords: Clay, supports, sintering, porosity, mechanical and chemical resistance.

\section{Introduction}

The supports are prepared by shaping of a ceramic powder followed with consolidation by sintering. The Shaping is possible if the paste formed from the powder, has a rheological properties of those neighboring of the clay [1,2]. The shaping method depends on the geometry of the final product and the tubular configuration is well suited for tangential filtration.

The different steps for preparing ceramic materials is the choice of the nature and particle size of the ceramic powder, the choice of organics additions, the optimal volume of water, the time of mixing and kneading, the aging time paste, shaping by extrusion, and the time of drying and sintering $[3,4]$. The base material used for the preparation of these materials is Moroccan clay of the Meknes-Tafilalet region. Due to mechanical, thermal and chemical performance of the rock and its abundance in nature, it turned out that it may be the basic raw material for producing ceramic single-channel for micro and ultrafiltration membranes.

Several studies have been conducted in this field, with use of local clay and the organics additions very expensive $[5,6,7,8]$, and in order to produce porous supports and chemically efficient, thermally and mechanically with a lower cost of production, we have employed the wood powder as an organic addition in the elaboration of these supports. In this work, we report the fabrication of tubular macro-porous ceramic support from Moroccan clay by extrusion followed by sintering. The characteristics of the support were discussed as a function of sintering temperature.

1. Elaboration of ceramic mono-channel supports:

\section{Materials And Methods}

The figure 1 shows the different steps for the preparation of the ceramic mono-channel supports with a clay rock for a microfiltration and ultrafiltration membranes. 


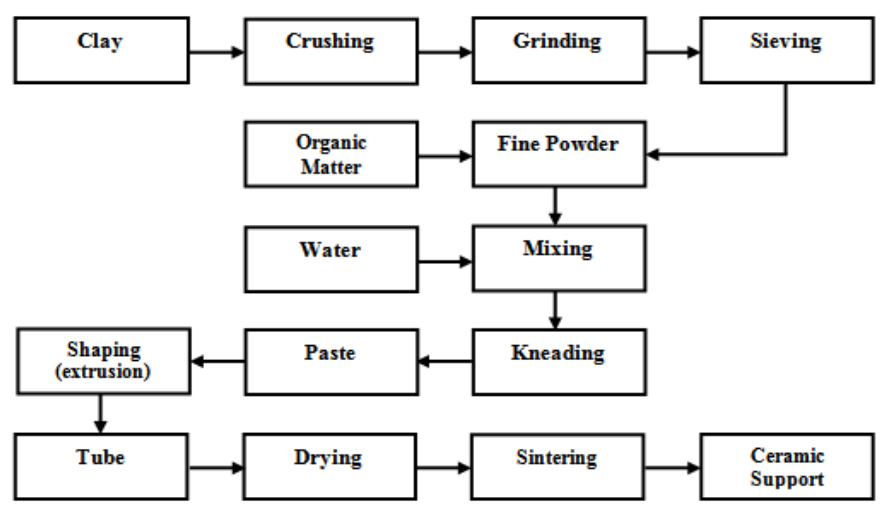

Figure 1: Steps for the preparation of the macro-porous ceramic supports

\subsection{Preparation of the ceramic paste:}

The optimal formulation of the ceramic precursor paste was carried out in an empirical way [1, 2]. The plastic paste was prepared from the clay powder mixed with the organic additives and water. Plasticizer and binder are required to prepare paste with rheological properties allowing the shaping by extrusion, drying and baking.

After study the different sizes, our choice was fixed on the use of the powders with the particle sizes less than $400 \mu \mathrm{m}$. The maximum use of the organic matter is $15 \%$ by weight of the wood powder, seen its availability in large quantities and less costly (solid waste from the wood industry) in order to obtain the best final characteristics of the porosity and the mechanical resistance. Table 1 present the parameters of the formulation of the used clay.

Table 1: Parameters of the formulation of the used clay

\begin{tabular}{|c|c|}
\hline Formulation & F15 \\
\hline Time of mixing (min) & 15 \\
\hline Time of kneading (min) & 20 \\
\hline Volume of water $(\mathbf{m l} / \mathbf{K g})$ & 330 \\
\hline Aging time $(\mathbf{h})$ & $>72$ \\
\hline
\end{tabular}

\subsection{Shaping of the tubes and thermal treatment:}

The paste is extruded by an extruder by mono-channel tubes. The length of the extruded tubes varied from $50 \mathrm{~cm}$ to $1 \mathrm{~m}$. The elaborated wet tubes are cut to different lengths and left in the open air for drying 3 days at maximum, all depending on the climate and the content of water introduced into mixing, After drying, the supports are treated by a thermal treatment in a programmable furnace at different final temperatures in order to finale consolidation for the shaping tubes. Figure 2 shows the thermal program.

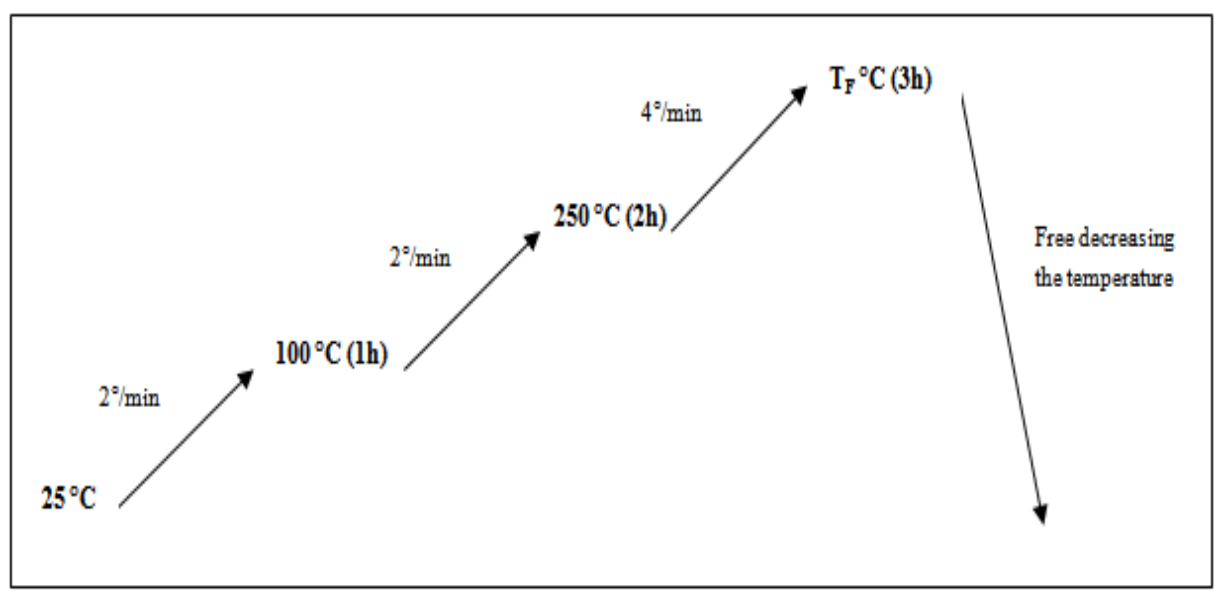

Figure 2: Thermal Program for clay tubes

All of the tubes are prepared sintered at 800,900 and $1000{ }^{\circ} \mathrm{C}$ and the final sintering time is 3 hours (Figure 3). 

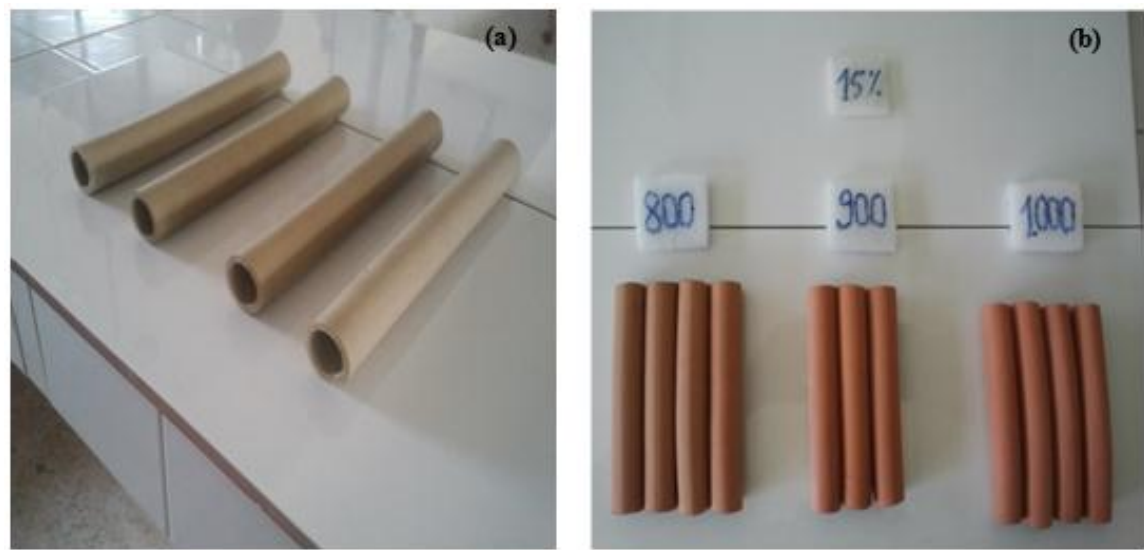

Figure 3: Tubular ceramic supports (S15), (a) before sintering and (b) after sintering $(800,900$ and 1000$){ }^{\circ} \mathrm{C} / 3 \mathrm{~h}$

\section{Permeability tests:}

The tests of permeability were carried out using on a laboratory pilot plant. Figure 4 gives the diagram of the laboratory pilot.

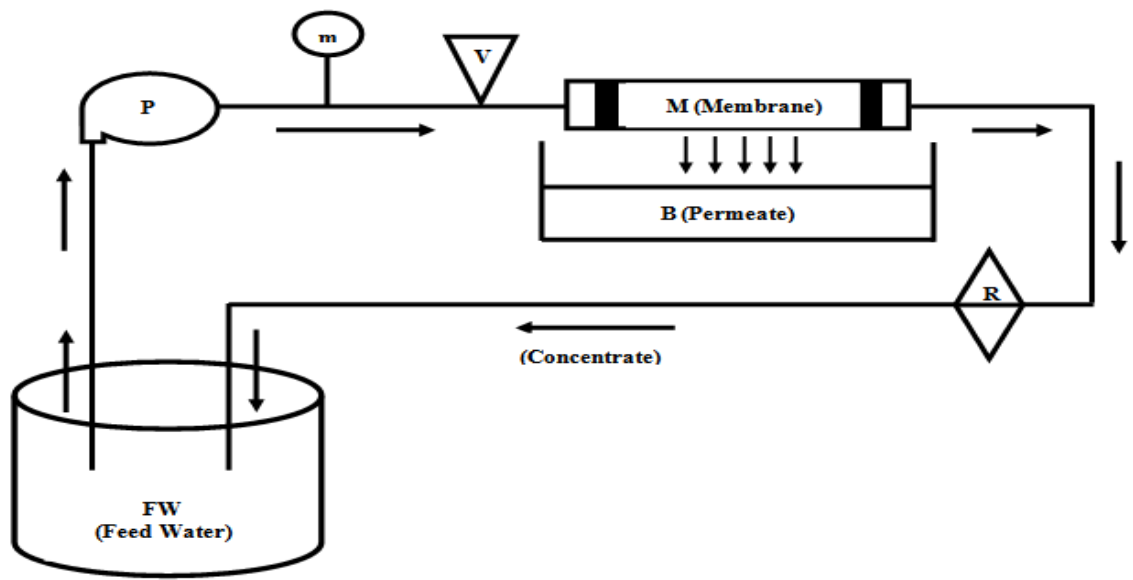

Figure 4: Pilot of the tangential filtration at the laboratory scale

Electric pump with adjustable flow rate $(\mathrm{P})$, manometer $(\mathrm{m})$, safety valve $(\mathrm{V})$, membrane module $(\mathrm{M})$, regulator of pressure $(\mathrm{R})$, permeate water $(\mathrm{B})$, feed water $(\mathrm{FW})$.

\section{Characterization of Moroccan clay:}

\section{Results And Discussion}

\subsection{Quantitative chemical analysis:}

The chemical compositions for the clay to the raw state are performed by X-ray Fluorescence $[9,10]$, the results is given in table 2 .

Table 2: Chemical composition of clay

\begin{tabular}{|c|c|c|c|c|c|c|c|c|}
\hline $\begin{array}{c}\text { Formula of } \\
\text { oxides }\end{array}$ & $\mathbf{S i O}_{\mathbf{2}}$ & $\mathbf{A l}_{2} \mathbf{O}_{\mathbf{3}}$ & $\mathbf{C a O}$ & $\mathbf{F e}_{2} \mathbf{O}_{3}$ & $\mathbf{M g O}$ & $\mathbf{M n O}$ & $\mathbf{N a}_{2} \mathbf{O}$ & $\mathbf{K}_{2} \mathbf{O}$ \\
\hline Mass percentage & 57,61 & 16,97 & 13,20 & 5,10 & 2,60 & 0,11 & 0,67 & 2,60 \\
\hline
\end{tabular}

It reveals that the clay powder is essentially formed of large amount of oxides silica and alumina in lower proportion with $75 \%$ by total mass, that allows concluding the mechanical efficiency of clay, and we noted the presence of a very large percentage of iron oxide about 5,10\% responsible for the red coloring of ceramic supports after thermal treatment [1]. 


\section{Characterization of supports:}

\subsection{Thermal Program:}

The sintering temperature is an important parameter which controls the cracteristics of final products such as: porosity, mechanical and chemical resistance. For this, the field of sintering temperature is varied between 800 and $1000{ }^{\circ} \mathrm{C}$. The adapted thermal program was shosen for several reasons including $[1,2,3]$ :

- At $100{ }^{\circ} \mathrm{C}$, we have a bearing the $1 \mathrm{~h}$ to ensure slowly the evaporation of the moisture of the water molecules.

- At $250{ }^{\circ} \mathrm{C}$, we have a level for 2 hours to degrade the organic matter (wood powder) and to leave the pores to the inner of the elaborated parts. Finally, we have the bearings of final sintering temperatures $\left(800,900\right.$ and $\left.1000^{\circ} \mathrm{C}\right)$ during $3 \mathrm{~h}$.

- Knowing that the rapid degradation of the added organic matter can causes the defects in the ceramic structure. For this reason, we chose to apply a slow rise in temperature up to $250{ }^{\circ} \mathrm{C}$ (cooking speed is $2 \% \min )$

\subsection{Porosity test by water:}

The principle of this test is to measure the percentage of total pore volume relative to the total mass of the dry sample by using the water for 24 hours at $25^{\circ} \mathrm{C}$, according to the following equation [11]:

With:

$$
P=\left(M_{W} / M_{D}\right) \times 100
$$

P: total porosity (\%);

$\mathrm{M}_{\mathrm{W}}$ : mass of water which absorbed the equivalent pore volume (g);

$\mathrm{M}_{\mathrm{D}}$ : mass of dry sample $(\mathrm{g})$.

Figure 5 gives the graphical representation of the total porosity versus the final sintering temperatures for $15 \%$ of the supports of the organic additions (S15).

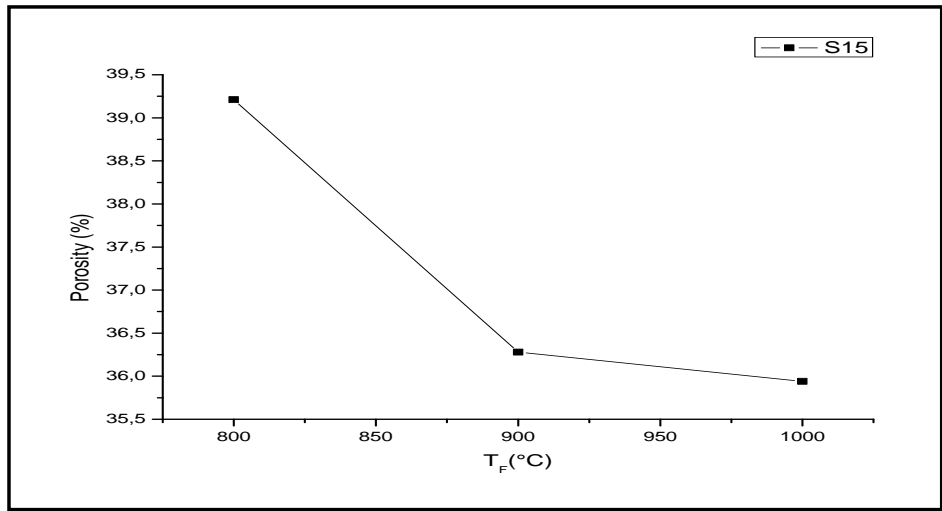

Figure 5: Total porosity versus the final sintering temperature for supports S15

The total porosity decreases with increasing temperature of the final sintering (of $39,21 \%$ to $35,94 \%$ ), and also the value of porosity is very important to the lowest temperature $\left(800^{\circ} \mathrm{C}\right)$ with a mechanical resistance very low, because the welding clay grains is not performed at this temperature good way [1].

\subsection{Chemical resistance:}

The test of chemical resistance was carried out on samples ceramic supports (S15), treated at different final sintering temperatures in acid medium $\left(\mathrm{HNO}_{3}\right)$ and basic $(\mathrm{NaOH})$ at various concentrations at $25^{\circ} \mathrm{C}$ for 24 hours $[1,2]$. The results of the chemical attack are presented in tables 3 and 4.

Table 3: Mass loss of the samples as a percentage of supports S15 after the acid attack at different concentrations of $\mathrm{HNO}_{3}$ for different final sintering temperatures

\begin{tabular}{|c|c|c|c|}
\hline 3 & 800 & 900 & 1000 \\
\hline Concentration & \multicolumn{3}{|c|}{$\Delta \mathrm{m} / \mathrm{m}(\%)$} \\
\hline $1 \mathrm{~N}$ & 1,62 & 1,15 & 1,11 \\
\hline $0,3 \mathrm{~N}$ & 0,89 & 0,75 & 0,69 \\
\hline
\end{tabular}


Table 4: Mass loss of the samples as a percentage of supports S15 after the basic attack at different concentrations of $\mathrm{NaOH}$ for different final sintering temperatures

\begin{tabular}{|c|c|c|c|}
\hline $\mathbf{T}_{\mathbf{F}}\left({ }^{\circ} \mathbf{C}\right) / \mathbf{3 h}$ & 800 & 900 & 1000 \\
\hline Concentration & \multicolumn{3}{|c|}{$\Delta \mathrm{m} / \mathrm{m}(\%)$} \\
\hline $1 \mathbf{N}$ & 0,42 & 0,29 & 0,28 \\
\hline $0,3 \mathbf{N}$ & 0,17 & 0,12 & 0,10 \\
\hline
\end{tabular}

The analysis of the results of the chemical resistance shows that the mass loss varied between 0,69 and $1,62 \%$ for the acid attack, and varied between 0,10 and $0,42 \%$ for the basic attack, for the tubular supports (S15) treated at different final sintering temperatures, the results show that the elaborated supports are characterized by a good chemical resistance to corrosion.

\subsection{Mechanical resistance of the compression:}

The test of compression consists to subjecting a test specimen having a rectangular section, placed between the platens of a press, with two opposing axial forces [12, 13]. Figure 6 shows the evolution of the values of mechanical resistance of the compression for samples (F15) treated with different final sintering temperatures.

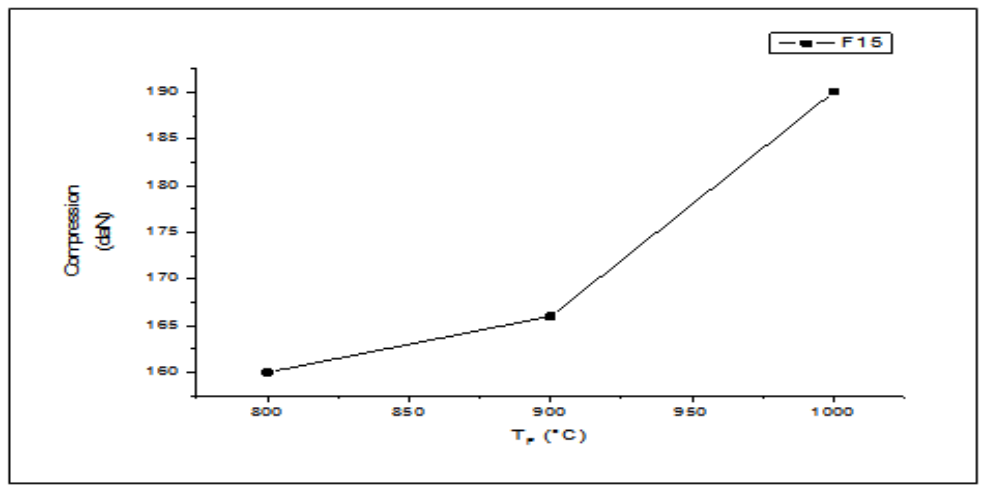

Figure 6: Mechanical resistance of the compression versus the final sintering temperature for specimens of formulation (F15)

The results show that the mechanical resistance increases with increasing the final sintering temperature (of $160 \mathrm{daN}$ to $190 \mathrm{daN}$ ). The maximum value of the mechanical compression resistance is observed at $1000{ }^{\circ} \mathrm{C}$, which shows that the sintering is best towards the high treatment temperatures. Therefore the ceramic supports sintered at this temperature during 3 hours are more effective mechanically compared to the other sintered supports at 800 to $900{ }^{\circ} \mathrm{C}$.

\subsection{Permeability tests:} $(\mathrm{F}=\mathrm{f}(\mathrm{P})$.

Figures 7 and 8 give the variations of the flow versus time $(\mathrm{F}=\mathrm{f}(\mathrm{t}))$ and versus circulation pressure

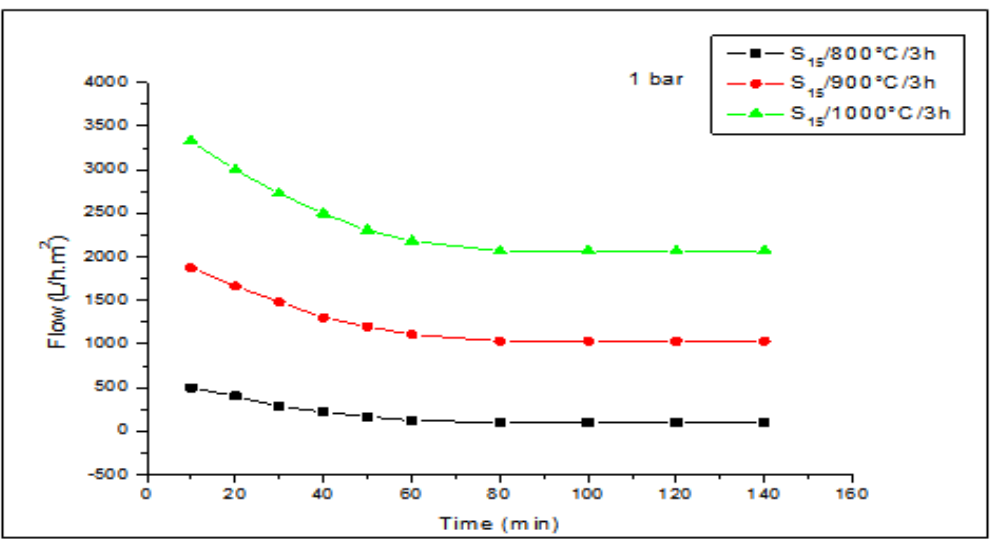

Figure 7: Variation of flow versus time for supports S15 treated at different final sintering temperatures (pressure $=1$ bar) 


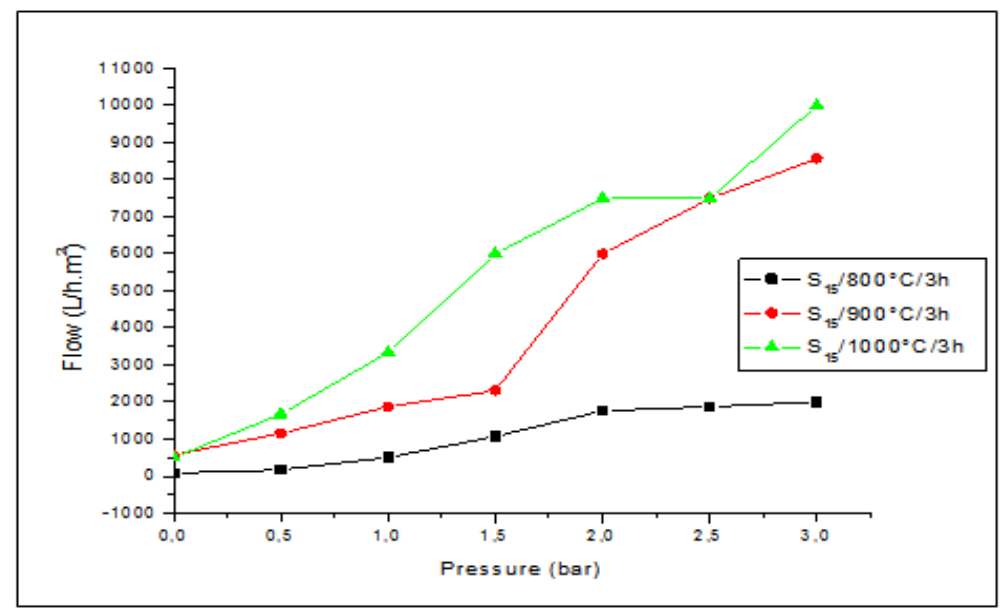

Figure 8: Variation of the flow versus pressure for supports S15 treated at different final sintering temperature

The results show that in the start of filtration, the values of the flow are higher for the all ceramic supports treated at 800,900 and $1000{ }^{\circ} \mathrm{C}$. Also, the flow decreases versus time (after 80 minutes of filtration for supports (S15): Flow $15 / 800 / 1 \mathrm{bar}=99 \mathrm{~L} / \mathrm{h} \cdot \mathrm{m}^{2}$; Flow $15 / 900 / 1 \mathrm{bar}=1033 \mathrm{~L} / \mathrm{h} \cdot \mathrm{m}^{2}$ and Flow $\mathrm{Sl}_{\mathrm{S} 15 / 1000 / 1 \mathrm{bar}}=2066 \mathrm{~L} / \mathrm{h} \cdot \mathrm{m}^{2}$ ), this can be explain to the phenomenon of concentration polarization [14], by the formation of the very thin water layer at the interface to the water-surface internal of the ceramic support, the concentration of this layer liquid is higher than that the feed solution, and also remain stationary and decreases the pore size for the supports.

The results show that the permeate flow increases versus pressure for them supports treated at 900 and $1000{ }^{\circ} \mathrm{C}$, the value of flow varied from the Flow $15 / 900=1152 \mathrm{~L} / \mathrm{h} \cdot \mathrm{m}^{2}$ for $0,5 \mathrm{bar}$ to Fow $\mathrm{F}_{\mathrm{S} 15 / 900}=8562 \mathrm{~L} / \mathrm{h} \cdot \mathrm{m}^{2}$ for 3 bar and Flow ${ }_{\mathrm{S} 15 / 1000}=1664 \mathrm{~L} / \mathrm{h} \cdot \mathrm{m}^{2}$ for 0,5 bar to Flow $\mathrm{S}_{\mathrm{S} 15 / 1000}=9989 \mathrm{~L} / \mathrm{h} \cdot \mathrm{m}^{2}$ for $3 \mathrm{bar}$.

\section{Conclusion}

In this work a new support of microfiltration and ultrafiltration membranes was prepared from natural powders derived from Moroccan clay. This kind of ceramic support presents the following characterizations:

- A good improvement of sintering of the supports according to different temperatures.

- The values of the porosity of the treated supports at 900 and $1000{ }^{\circ} \mathrm{C}$ are very similar but with different mechanical resistance.

- The chemical attack is very important when the solutions are very acidic and almost zero in the case of the basic solutions for the supports $15 \%$ to the organic matter.

- The specimen of formulating (F15) treated at $1000{ }^{\circ} \mathrm{C}$ during $3 \mathrm{~h}$ is characterized by a good mechanical resistance of the compression.

- The ceramics supports $\mathrm{S} 15$ treated at $1000{ }^{\circ} \mathrm{C} / 3 \mathrm{~h}$ present the very higher permeate flow.

- The sintered supports $\mathrm{S} 15$ at $1000{ }^{\circ} \mathrm{C}$ during 3 hours are characterized by a good state of sintering, best porosity, excellent chemical and mechanical performances and good permeability.

These results show that the ceramic supports the $15 \%$ of the organic matter sintered at $1000{ }^{\circ} \mathrm{C} / 3 \mathrm{~h}$ can be used for the deposition of the layers for the microfiltration and ultrafiltration membranes.

\section{Acknowledgements}

The author express their thanks to all those that participated in the realization of this present work, especially Prof. Dr. Lahcen MESSAOUDI: director of the thesis, for his valuable advice, his availability and for all the efforts he has been provided to ensure a better quality of work, many thanks also go to Fatima El AZHAR, Doctor in engineering process for his proofreading assistance and for his guidance.

\section{References}

[1] L. Messaoudi, Preparation of new ceramic supports microporous for inorganic membranes based Moroccan clays, Thesis Third Cycle, Sidi Mohammed Ben Abdellah University, Faculty of Sciences Dhar el Mehraz, Fez, Morocco, 1987.

[2] A. Bouisfi, Elaboration and characterization of supports based clay for microfiltration and ultrafiltration membranes, Diploma of higher studies DEA, Sidi Mohammed Ben Abdellah University, Faculty of Sciences Dhar el Mehraz, Fez, Morocco, 1997.

[3] A. Lahsini, Development, characterization and study of the sintering of membranes based local clay. Application to tangential microfiltration, doctoral thesis of state, Sidi Mohammed Ben Abdellah University, Faculty of Sciences Dhar el Mehraz, Fez, Morocco, 1999.

[4] A. Larbot, Ceramic membranes: development and future developments, $I^{\text {st }}$ school of summer Franco-Maghrebine membrane science and technology under the theme: membrane technology applied to purification of water and treatment of liquid effluent, Hassan II University, Faculty of Science and Technology, Mohammedia, Morocco, 2004, 33p. 
[5] N. El moudden, A. El ghazouali, S. Rakib, M. Sghyar, M. Rafiq, A. Larbot, and L. Cot, New supports of the membrane based clay fireclay, ANN CHIMSC, 26 (3), 2001, 41-48.

[6] N. Saffaj, M. Persin, S. Alami younsi, A. Albizane, M. Cretin, and A. Larbot, Elaboration and characterization of microfiltration and ultrafiltration membranes deposited on raw support prepared from natural Moroccan clay: application to filtration of solution containing dyes and salts, Appl. Clay Sci, 31, 2006, 110-119.

[7] I. Jedidi, S. Khemakhem, A. Larbot, and R. Ben amar, Elaboration and characterization of fly ash based mineral supports for microfiltration and ultrafiltration membranes, Ceramics International, 35, 2009, 2747-2753.

[8] A. Majouli, S. Tahiri, S. Alami younssi, H. Loukili, and A. Albizane, Elaboration of new tubular ceramic membrane from local Moroccan Perlite for microfiltration process : application to treatment of industrial wastewaters, Ceramics International, 38, 2012, 4295-430.

[9] Y. Anbri, Elaboration and characterization of supports for membranes inorganic based clay of the Meknès-Tafilalet region, Diploma of Higher Studies DEA, Moulay Ismail University, Faculty of Sciences, Meknes, Morocco, 2005.

[10] A. El gamouz, H. Bendifi, M. El amane, L. Messaoudi, and N. Tijani, Physico-chemical characterisation of a clay rock from Meknes-Tafilalet region, J.Phys.Chem.News, 34, 2007, 120-125.

[11] X. Guillot, M. Al mukhtar, F. Bergaya, and J. M. Fleureau, Estimation of the porosity in a clay material, C.R.A.S., C.R. Géoscience, 334, 2002, 105-109.

[12] A. Sarhiri, Pasta white for ceramic tile, formulations, physico-chemical characterization and validation, doctoral thesis of state, Hassan II University, Faculty of Sciences Ain Chock, Casablanca, Morocco, 2003.

[13] B. Jacquot, Mechanical properties of biomaterials used in odontology, Virtual Medical University Francophone, French Society of Dental Biomaterials, Lille, France, 2010.

[14] S. Galaj, A. Wicker, J.P. Dumas, J. Gillot, and D. Garcera, Tangential microfiltration with unclogging of the ceramic membranes, The milk, 638-639, 1984, 129-140. 